\title{
Answers to Common Clinical Questions
}

\author{
Marjorie A. Bowman, MD, MPA, and Anne Victoria Neale, PhD, MPH
}

Again, we present a rich issue with great information to address common clinical questions. A common class of drug (proton pump inhibitors) and insufficiently common diet (high fiber content) are related to improved diabetes control. Four good health habits make a huge difference, especially for obese patients. Meaningful use is just not always that meaningful. Computed tomography scans for common chest complaints probably are overused in emergency rooms. Continuous insurance is important to receipt of prevention services, even for those with access to care when they do not have insurance. Practice-based research can be difficult to accomplish, yet can yield some good results-in this case, improved colon cancer screening rates. Consider hyperaldosteronism in patients with resistant hypertension. Reflect on the mistakes other family physicians report; we often learn from others' mistakes. Surgical mesh migration can cause many things, but would you guess it would cause symptoms of irritable bowel syndrome? A nice primer on what is known about chemoprevention of prostate cancer. And, how to influence care outcomes: high-leverage, not just measurable, activities. (J Am Board Fam Med 2012;25:1-4.)

\section{In This Issue}

The biggest surprise: proton pump inhibitors and diabetes.

The second biggest surprise: a case of surgical mesh and irritable bowel syndrome.

The least surprising to practicing family physicians: electronic health records may meet federal definitions for meaningful use, but some aspects may not seem so useful in the office.

The best to quote in the office: 4 good health habits $=$ one-third the death rate; for obese individuals (body mass index $>30$ ), 4 good health habits $=$ one-seventh the death rate.

The best underutilized concept: high-leverage activities.

The best new clinical decision support: for influenza (highlighted at the 2011 meeting of North American Primary Care Research Group).

\section{Prevention}

Let's start with the best quote to use in behavior change: 4 good habits $=$ one-third the mortality rate-smoking, eating vegetables and fruits, ex-

Funding: none.

Conflict of interest: The authors are editors of the $7 A B F M$. ercising, and alcohol in moderation. You already know these because they are the focus of much behavioral change counseling. Matheson et $\mathrm{al}^{1}$ further note that this is even more true for obese individuals; those without any of the healthy habits have seven times the rate of death.

Although the national debate rages over the risks and benefits of prostate-specific antigen screening for early detection of prostate cancer, ${ }^{2}$ there is yet another significant area of controversy: chemoprevention. Violette and $\mathrm{Saad}^{3}$ provide the latest data to inform clinicians and their patients. It would be nice to say that we should just get informed consent for prostate-specific antigen testing or prostate cancer chemoprevention, but the amount and complexity of the data evidenced in this article can be difficult for doctors to sort out, let alone for uninitiated patients.

In a meta-analysis, Post et $\mathrm{al}^{4}$ report that dietary fiber improved diabetes control across several studies. Increasing the intake of high-fiber cereal and vegetables seems to be a good idea for patients with diabetes. All the studies were short term, so the longer use of fiber could magnify the effect further (perhaps through weight loss and decreased dietary glycemic index). Also, the higher-fiber diets possibly could delay or decrease the incidence of diabetes. 


\section{"Meaningful Use"}

Although we strive to achieve meaningful use to earn more federal dollars, we find that such meaningful use often is missing from current electronic systems. In a trial conducted in collaboration with local insurers, Crosson et $\mathrm{al}^{5}$ found that standalone electronic prescribing systems per se are not yet the efficiency boosters many expect-even to physicians who volunteer to use them! We are certain that a number of readers can identify with these physicians; they found the formulary and medication history frustrating because of inaccuracies, caused by many different factors. Paper "work-arounds" were common, requiring dual paper-work, and 2 practices stopped using the electronic systems. It is unclear if the system saved the physician or office staff any time or decreased phone calls related to suboptimal prescribing. Furthermore, insurance-based systems such as this one are also a problem for those patients without prescription medication coverage. Another article in this issue ${ }^{6}$ also shows that electronic records cannot necessarily produce good patient lists. Electronic resources, so truly desired in the imaginary world of computer perfection, often are wanting.

Recently, a study noted that many physicians believe their patients get too much medical care, ${ }^{7}$ and from my $(\mathrm{MAB})$ perspective, one of the areas that is most obvious is in the overuse of expensive testing in the emergency department. Coco and $\mathrm{O}^{\prime}$ Gurek $^{8}$ document the greatly increased use of chest computed tomography scans in the emergency department over time without a concurrent increase in significant medical diagnoses such as pulmonary embolism, one of the serious diagnoses that specifically can be identified through computed tomography and not other diagnostic modalities.

Given that Oregon community health centers will take care of those who are uninsured, it is curious that those patients with diabetes who were uninsured or only intermittently insured received only about one-half as many preventive measures recommended for those with diabetes than those who were continuously insured. ${ }^{9}$ How does this occur? Do the patients not understand that the clinics will continue to see and treat them? $\mathrm{Al}-$ though one rightly could interpret this article as a strong argument for continuous insurance coverage, it also should lead the health centers to rein- force to patients their opportunity to be seen even when not insured and to take care of as many of their preventive services whenever they are seen, no matter what the chief complaint is.

Crouch et $\mathrm{al}^{10}$ presents observational data that are probably the surprise of this issue for most family physicians: proton pump inhibitors were associated with substantially better diabetes control. This is not obvious from commonly known physiology, and may not be obvious to those in practice. We look forward to additional trials to confirm or refute this observation because proton pump inhibitors are widely available, remarkably safe, and have fewer side effects than many medications used to control diabetes.

The winning article by Ebell et $\mathrm{al}^{11}$ (selected for a Distinguished Paper Presentation at the North American Primary Care Research Group 2011 annual meeting) establishes an excellent history-based clinical decision rule that supports influenza diagnosis. These authors could predict those who did not need further influenza testing about two thirds of the time. This could be helpful for phone triage of patients during a busy influenza season.

\section{Practice-Based Research}

We have back-to-back articles reporting on development of an intervention to improve colon cancer screening from a practice-based network in Iowa (called IRENE). First, Daly et $\mathrm{al}^{6}$ present the process of recruiting and getting the study started in practices. Many difficulties were encountered. The practices could not readily identify their eligible patients; there were issues with the institutional review board approval process; there were issues with the US Postal Service. Only 20\% of the eligible patients returned informed consent forms. To our primary care researchers, these common logistic difficulties are all too familiar. However, it could be useful for practicing family physicians to understand some of the "behind the scenes" effort required to conduct primary care research, while also getting to see some of the fruits from this work, ie, the outcomes, as presented in the second report on this study. ${ }^{12}$ Stool testing for colon cancer, by postal mail-in, increased dramatically with the use of mailed educational materials to the patients. ${ }^{12}$ Most of the patients read and understood the materials and were more likely to speak to their physician about colon cancer screening. Thus, a lot of hard work, but a successful outcome. 
The Hawthorne effect-that mere attention, or an awareness that one is being studied, can change study outcomes- has forced the research community to create elaborate mechanisms, such as double-blinded, placebo-controlled trials, to determine the efficacy of medications or treatments. If this similar effect was operational in practice-based research, where it is often practices rather than individuals who are randomized, it would further complicate how we must undertake some of our most important studies. Fernald et $\mathrm{a}^{13}$ looked for this phenomena in practice-based research; at least in their circumstance, with the specific trial and practices, they could not (thankfully) detect evidence of a Hawthorne effect.

\section{Lessons Learned}

There are several informative articles in this issue that can guide us in practice. Lessons learned, sometimes after the fact, can be associated with disastrous outcomes. Ely et $\mathrm{al}^{14}$ asked physicians to describe a diagnostic error and what they had learned. Not surprisingly, many of the clinical situations involved very common symptoms, but what followed obviously was not the most common cause of those symptoms. Barnes ${ }^{15}$ presents the second biggest surprise of this issue (behind paintball injuries associated with lower glycosylated hemoglobin levels; see below): a patient was diagnosed with irritable bowel syndrome that was cured by removal of the surgical mesh that had migrated. Surgical mesh can be extremely useful in surgeries but can also cause baffling or difficult complications later. This case, where symptoms of irritable bowel syndrome actually caused by surgical mesh migration went undiagnosed for years, is consistent with Ely et al's ${ }^{14}$ article about mistakes.

A group of German researchers and family physicians tackled a clinical dilemma: in family medicine, should we, and how should we, consider hyperaldosteronism in patients with resistant hypertension? ${ }^{16}$ The answers are not clear cut, yet their findings are informative. Paintball injuries include some classic injuries that can be easily recognized if they are considered. ${ }^{17}$ With complaints of insomnia in adults, particularly women, obstructive sleep apnea should be considered. ${ }^{18}$ Premenopausal patients and those overweight or white were more likely to require additional views after screening mammograms. ${ }^{19}$ Finally, we have a study adding to the growing evidence that, to address the physician shortage, we should provide rural training dollars for residency education in rural and underserved environments. $^{20}$

In the next issue, look for articles about health care teams: debating, considering, and pushing teams to advance care in family medicine.

\section{References}

1. Matheson EM, King DE, Everett CJ. Healthy lifestyle habits and mortality in overweight and obese individuals. J Am Board Fam Med 2012;25:9-15.

2. U.S. Preventive Services Task Force. Screening for prostate cancer: draft recommendation statement. Available at http://www.uspreventiveservicestaskforce. org/draftrec3.htm Updated October 2011. Accessed October 14, 2011.

3. Violette PD, Saad F. Chemoprevention of prostate cancer: myths and realities. J Am Board Fam Med 2012;25:111-119.

4. Post RE, Mainous AG, King DE, Simpson KN. Dietary fiber for the treatment of type 2 diabetes mellitus: a meta-analysis. J Am Board Fam Med 2012;25:16-23.

5. Crosson JC, Schueth AJ, Isaacson N, Bell DS. Early adopters of electronic prescribing struggle to make meaningful use of formulary checks and medication history documentation. J Am Board Fam Med 2012; 25:24-32.

6. Daly JM, Xu Y, Ely JW, Levy BT. A randomized colorectal cancer screening intervention trial in the Iowa Research Network (IRENE): study recruitment methods and baseline results. J Am Board Fam Med 2012;25:63-72.

7. Sirovich BE, Woloshin S, Schwartz LM. Too little? Too much? Primary care physicians' views on US health care. Arch Intern Med 2011;171(17):1582-5.

8. Coco AS, O'Gurek DT. Increased emergency department computed tomography use for common chest symptoms without clear patient benefits. J Am Board Fam Med 2012;25:33-41.

9. Gold R, DeVoe JE, McIntire PJ, Puro JE, Chauvie SL, Shah AR. Receipt of diabetes preventive care among safety net patients associated with differing levels of insurance coverage. J Am Board Fam Med 2012;25:42-49.

10. Crouch M, Mefford IN, Wade EU. Proton pump inhibitor therapy associated with lower glycosylated hemoglobin levels in type 2 diabetes. J Am Board Fam Med 2012;25:50-54.

11. Ebell MH, Afonso AM, Gonzales R, Stein J, Genton $\mathrm{B}$, Senn N. Development and validation of a clinical decision rule for the diagnosis of influenza. J Am Board Fam Med 2012;25:55-62.

12. Levy BT, Daly JM, Xu Y, Ely JW. Mailed fecal immunochemical tests plus educational materials to improve colon cancer screening rates in Iowa Re- 
search Network (IRENE) practices. J Am Board Fam Med 2012;25:73-82.

13. Fernald DH, Coombs L, DeAlleaume L, West D, Parnes B. An assessment of the Hawthorne effect in practice-based research. J Am Board Fam Med 2012; 25:83-86.

14. Ely JW, Kaldjian LC, D'Alessandro DM. Diagnostic errors in primary care: lessons learned. J Am Board Fam Med 2012;25:87-97.

15. Barnes MG. Irritable bowel syndrome: a "mesh" of a situation. J Am Board Fam Med 2012;25:120-123.

16. Schmiemann G, Gebhardt K, Hummers-Pradier E, Egidi G. Prevalence of hyperaldosteronism in primary care patients with resistant hypertension. J Am Board Fam Med 2012;25:98-103.
17. Sbicca JA, Hatch RL. Target lesions and other paintball injuries. J Am Board Fam Med 2012;25:xxx-xxx.

18. Glidewell RN, Roby EK, Orr WC. Is insomnia an independent predictor of obstructive sleep apnea? J Am Board Fam Med 2012;25:124-127.

19. Justice TD, Stiff JH, Myers JA, Milam MR. Prediction of incomplete screening mammograms based on age and race. J Am Board Fam Med 2012;25:128130.

20. Xierali IM, Sweeney S, Phillips Jr. R, Bazemore A, Petterson S. Increasing graduate medical education (GME) in critical access hospitals (CAH) could enhance physicians recruitment and retention in rural America. J Am Board Fam Med 2012;25:7-8. 